DOI: 10.21608/zvjz.2016.7852

\title{
Determination of Ochratoxin A Residues in Some Animal and Plant Milk Products
}

\author{
Seham El-Badry \\ Educational Veterinary Hospital, Faculty of Veterinary Medicine, Zagazig University, 44511, \\ Egypt
}

Article History: Received: 18/5/2016 Received in revised form: 10/8/2016 Accepted: 3/9/2016

\begin{abstract}
Milk and milk products are considered major foods for all ages in humans. They represent primary sources for protein, fat and minerals. Ochratoxins are fungal secondary metabolites which are produced either due to fungal growth in many food ingredients such as cereals or in animal feed and subsequently excreted in animal by-products including milk and milk products. Ochratoxins have public health concern due to their nephrotoxic and carcinogenic effects. Thus, this study was designed to determine the residual concentrations of Ochratoxin A (OTA) using Flurometer in some marketed dairy products in Zagazig City, Egypt. The examined dairy products included pasteurized cow's milk, dried skimmed milk, baby milk formula and wheat milk groats (Cerelac). Ochratoxin A was detected in all the examined samples with different concentrations. The results declared that all pasteurized cow's milk samples and $80 \%$ of wheat milk groats had OTA levels which exceeded the maximum permissible limit (5 ng/g) recommended by World Health Organization. Calculation of the estimated daily intake for four age groups (babies, children, adolescents and adults) was carried out. It could be concluded that continuous screening of dairy products' content of OTA is essential to minimize the public health hazards of such toxin.
\end{abstract}

Keywords: Ochratoxin A, Residues, Milk, Flurometer

\section{Introduction}

Dairy products such as cow's milk, dried milk, baby milk formula and milk cereals are considered important foods in the human diet. They are good sources of protein, fat, and major minerals especially for infants and children [1].

Toxigenic strains of the fungi produce secondary metabolites called mycotoxins, which contaminate various food substances and agricultural crops [2]. The major fungi that produce mycotoxins include Aspergillus, Penicillium and Fuzarium. These fungi can produce aflatoxins and ochratoxins (OT).

Foodborne mycotoxins retained their importance in Egypt and other countries because of their impact on human health, animal production and economy [3]. Dairy products are among the major sources of mycotoxins in Egypt [2].
Ochratoxin A (OTA) is classified as a possible human carcinogen (category 2B), thus, there is a concern about the potential long term effects due to the continuous exposure to this toxin [4]. In addition, OTA has been reported to have toxic effects on kidney and teratogenic properties [5].

Human's exposure to OTA is usually through consumption of food which has been directly contaminated with fungi, or foodproducts derived from exposed animals, and probably also by inhalation of contaminated dust [6,7]. Milk and milk products are less frequently considered possible sources for human exposure to OTA. However, OTA was detected in 5 of 36 cow's milk samples from Sweden with a concentration range of 10 to 40 $\mathrm{ng} / \mathrm{L}$ [8]. It is noteworthy that even low concentrations of OTA in milk may have serious complications among consumers of 
large quantities such as children, and contribute to a significant portion of the total dietary intake [1].

Therefore, evaluating milk and milk products for their residual levels of OTA is important for safety and health purposes. Thus, the present study aimed to determine the levels of OTA in milk and milk products (pasteurized cow's milk, dried skimmed milk, baby milk formula and wheat milk groats) marketed in Zagazig City, Sharkia Governorate, Egypt. Additionally, the public health importance was also discussed.

\section{Material and Methods}

\section{Samples}

Forty dairy products included pasteurized cow's milk, dried milk; baby milk formula and wheat milk groats (Cerelac) (10, each) were collected randomly from different localities in Zagazig City, Sharkia Governorate, Egypt during 2015. Collected samples were transferred directly to the Central laboratory, Faculty of Veterinary Medicine, Zagazig University, Zagazig, Egypt for OTA determination.

\section{Analytical method}

The quantitative determination of ochratoxin A by Flurometer (VICAM, Series 4) was done according to the manufacturer's instructions and the method developed before [9]. All the used reagents were of analytical grade. In brief, $50 \mathrm{ml}$ or $50 \mathrm{~g}$ of samples were extracted in $100 \mathrm{~mL}$ methanol:water (80:20) three times. The extracts were diluted four times with phosphate buffer saline (PBS) and filtrated using glass microfibre filter. A volume of $20 \mathrm{~mL}$ filtered diluted extract were passed through OchraTest ${ }^{\circledR}-\mathrm{P}$ affinity column at a rate of about $1-2$ drops/sec. Then, $10 \mathrm{~mL}$ of $0.1 \%$ Tween $20 / \mathrm{PBS}$ were passed through the column at a rate of 1-2 drops/sec. The glass cuvette (VICAM part \# 34000) was placed under OchraTest $^{\mathrm{TM}}$ column and $1.5 \mathrm{~mL}$ OchraTestTM elution solution were added into glass syringe barrel. The syringe barrel was then filled with $10 \mathrm{~mL}$ of PBS, that was passed through the column at a rate of 1-2 drops/sec.
Elution was carried out at a rate of $1 \mathrm{drop} / \mathrm{sec}$; and the sample eluate was collected $(1.5 \mathrm{~mL})$ in a glass cuvette. Following thorough mixing, the cuvette was immediately placed into calibrated fluorometer. Ochratoxin concentration was read after $60 \mathrm{sec}$. The detection limit was from $0.1 \mathrm{ppb}$ to $100 \mathrm{ppb}$.

After the analysis of all the samples, statistical analysis was done using Student's $t$-test to analyze the significance of the results at $\mathrm{p}<$ 0.05 .

\section{Estimated daily intake calculation}

Estimated daily intake (EDI) (ng/kg/day) of OTA was calculated for the four age groups consuming milk products based on the following formula:

\section{EDI $(\mathrm{ng} / \mathrm{kg} /$ day $)=$ OTA concentration $\mathrm{x}$ Ingestion rate/Body weight}

The examined age groups included babies $(0-2$ years with ingestion rate of $220 \mathrm{~mL}(\mathrm{~g})$; body weight $7 \mathrm{~kg}$ ); children (2-11 years with ingestion rate of $160 \mathrm{~mL}(\mathrm{~g})$; body weight 35 $\mathrm{kg}$ ); adolescents (11-19 years with ingestion rate of $130 \mathrm{~mL}(\mathrm{~g})$; body weight $60 \mathrm{~kg}$ ), and adults (more than 19 years with ingestion rate of $80 \mathrm{~mL}(\mathrm{~g})$; body weight $70 \mathrm{~kg}$ ) [10].

\section{Results and Discussion}

Several studies provided evidence that intake of dairy products is related to improved bone health and lower risk of cardiovascular diseases, hypertension and type 2 diabetes [11].

Ochratoxin A is among the most important mycotoxins in many countries. Some Aspergillus and Penicillium fungi produce OTA in moderate climates, and contaminate commodities such as cereals and cereal foods and may be excreted in milk if animals received them in their feed [2]. Mycotoxins are considered nephrotoxic and carcinogenic substances and are classified as possible human carcinogen [4].

It is clear from the obtained results that all tested samples contained OTA with different concentrations. Pasteurized cow's milk had the highest OTA concentrations with a range of 
8.5 to $13.6 \mathrm{ng} / \mathrm{g}$ and a mean value of $10.94 \pm$ a mean value of $7.14 \pm 0.85 \mathrm{ng} / \mathrm{g}$ (Figure 1 ). $0.97 \mathrm{ng} / \mathrm{g}$ followed by wheat milk groats with

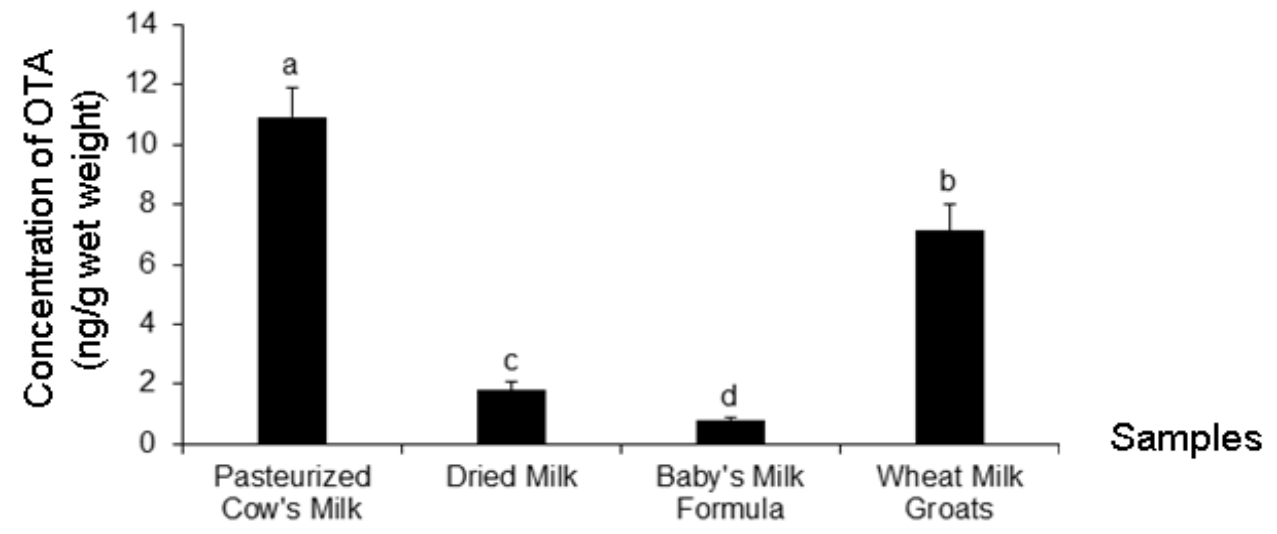

Figure 1: Ochratoxin A concentration (ng/g wet weight) in the examined dairy products. Values are expressed as mean \pm SE. Columns carrying different superscript letter are significantly different with each other at $\mathbf{p}<\mathbf{0 . 0 5}$.

The concentrations ranged from 1.10 to $2.91 \mathrm{ng} / \mathrm{g}$ in dried milk powder with a mean concentration of $1.81 \pm 0.29 \mathrm{ng} / \mathrm{g}$ (Figure 1). Baby milk formula was the lowest in its OTA content with a mean value of $0.81 \pm 0.08 \mathrm{ng} / \mathrm{g}$ (Figure 1). It is clear from the obtained results that OTA can resist processing and pasteurization of milk. In accordance, OTA was detected in cow's milk with low concentration of 5-8 ng/L [8]. In addition, OTA was reported to contaminate 14 commercial brands of ready to use infant formula in Italy with the percentage of $72 \%$ and concentrations ranged from 35.1 to 689.5 $\mathrm{ng} / \mathrm{L}$ [12]. Another study in Turin, Italy, examined OTA levels in 32 colonial cheeses made from raw milk, the results revealed that 6 samples $(18.8 \%)$ were positive for the presence of OTA with values between 18.4 and $146.0 \mu \mathrm{g} / \mathrm{kg}$ in the interior part and between 1.0 and $262.2 \mu \mathrm{g} / \mathrm{kg}$ in the cheese hull [13]. In contrary, no OTA was detected in infant formula in an earlier study in Norway, but in the same study OTA was highly detected in cow's milk [14]. The presence of OTA in cow's milk and milk products could be originated from animal feed. In agreement with this hypothesis, it was calculated that a cow fed with an oral dose of $1 \mathrm{~g}$ of OTA/day would result in $100 \mu \mathrm{g} / \mathrm{kg}$ of OTA in milk, corresponding to a transfer ratio of $0.01 \%$ [15].

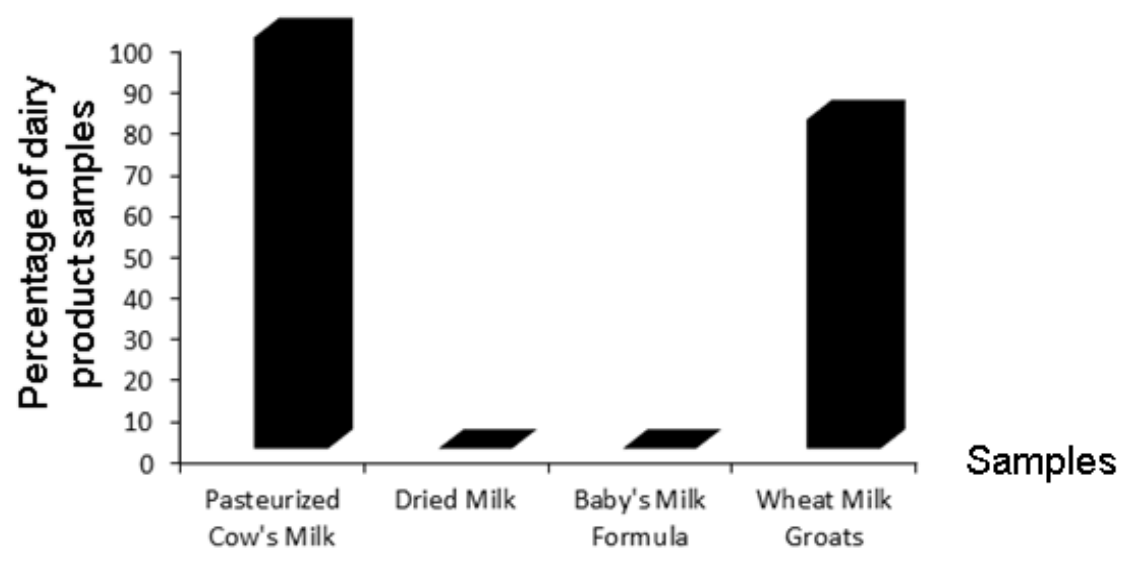

Figure 2: Percentage of different dairy product samples having Ochratoxin A residues over the maximum permissible limit (MPL) (5 ng/g) according to WHO 1991 [16]. 
The results shown in Figure (2) declared that all pasteurized cow's milk samples and $80 \%$ of wheat milk groats had OTA more than the maximum permissible limit (MPL) which is $5 \mathrm{ng} / \mathrm{g}$ [16]. However, none of the dried milk samples and baby milk formula exceeded this MPL.

The Scientific Committee of Food [17] evaluated the toxicity of OTA and concluded that reducing OTA in food is required to protect the class of people at high risk (babies and children), who consume a lot of milk and milk products in comparison with other age groups. OTA toxicity was also evaluated by the joint FAO/WHO Expert Committee on Food Additives [3], and established $14 \mathrm{ng} / \mathrm{kg}$ body weight as the tolerable daily intake of OTA. Thus, the calculated daily intake (EDI) of OTA in the four age groups consuming milk as clear in Table 1.

The calculated EDI showed that babies (02 years) are at high risk if they consumed any of the examined dairy products, whereas the EDI values were $343.89,56.82,25.39$ and 224.4 (ng/kg/day) for pasteurized cow's milk, dried milk, baby milk formula and wheat milk groats, respectively (Table 1). Both children (2-11 years) and adolescents (11-19 years) will be at exposure risk for OTA if they consumed cow's milk or wheat milk groats (Table 1). However, there will be no OTA risk if they consumed any of the examined products.

Table 1: Estimated daily intake (EDI) (ng/kg/day) of Ochratoxin A in different age groups of people

\begin{tabular}{lcccc}
\hline Age & $\begin{array}{c}\text { Babies } \\
(\mathbf{0 - 2} \text { years })\end{array}$ & $\begin{array}{c}\text { Children } \\
(\mathbf{2 - 1 1} \text { years })\end{array}$ & $\begin{array}{c}\text { Adolescents } \\
(\mathbf{1 1 - 1 9} \text { years })\end{array}$ & $\begin{array}{c}\text { Adults } \\
\text { (more than 19 years) }\end{array}$ \\
\hline Pasteurized Cow's Milk & 343.89 & 50.02 & 23.71 & 12.51 \\
\hline Dried Milk & 56.82 & 8.27 & 3.92 & 2.06 \\
\hline Baby Milk Formula & 25.39 & 3.69 & 1.75 & 0.92 \\
\hline Wheat Milk Groats & 224.4 & 32.64 & 15.47 & 8.16 \\
\hline
\end{tabular}

\section{Conclusion}

It is concluded from this study that great care should be taken when introducing dairy products to babies. Continuous screening for dairy products' content of OTA must be performed by the specific authorities.

\section{Conflict of interest}

The author has no conflict of interest to declare.

\section{References}

[1] Lampert, L.M. (1984): The minerals and water in milk. In Modern Dairy Products, Chemical Publishing, Co., New York, pp. 57-70.

[2] Darwish, W.S.; Ikenaka, Y.; Nakayama, S.M. and Ishizuka, M. (2014): An overview on mycotoxin contamination of foods in Africa. J Vet Med Sci, 76(6):789-97.
[3] Joint FAO/WHO Expert Committee on Food Additives. Meeting, World Health Organization \& International Program on Chemical Safety (2001): Safety evaluation of certain mycotoxins in food (No. 74). Food \& Agriculture Organization.

[4] IARC Working Group on the Evaluation of Carcinogenic Risks to Humans, and International Agency for Research on Cancer. "Some naturally occurring substances: food items and constituents, heterocyclic aromatic amines and mycotoxins/this publication represent the views and expert opinions of an IARC Working Group on the Evaluation of Carcinogenic Risks to Humans, which met in Lyon, 9-16 June 1992." (1993).

[5]Kuiper-Goodman, T. (1996): Risk assessment of ochratoxin A: an update. Food Add Contam, 13(suppl): 53-57.

[6] Di Paolo, N.; Guarnieri, A.; Loi, F.; Sacchi, G.; Mangiarotti, A.M. and Di Paolo, M. (1993): Acute renal failure from 
inhalation of mycotoxins. Nephron, 64(4): 621-625.

[7] Speijers, G.J.A. and Van Egmond, H.P. (1993): Worldwide ochratoxin A levels in food and feeds. Colloques-Institut National De La Sante Et De La Recherche Medicale Colloques Et Seminaires, pp.85.

[8] Breitholtz-Emanuelsson, A.; Olsen, M.; Oskarsson, A.; Palminger, I. and Hult, K. (1993): Ochratoxin A in cow's milk and in human milk with corresponding human blood samples. J AOAC Int, 76(4): 842846.

[9] El-Ghareeb, W.R.; Darwish, W.S.; Tharwat, A.E.; El-Desoky, K.I. and Hussein, M.A. (2013): Aflatoxin and ochratoxin A residues in some Egyptian meat additives. Life Sci J, 10(4):34113416.

[10] Sebastian, R.S.; Goldman, J.D.; Enns, C.W. and LaComb, R.P. (2010): Fluid milk consumption in the United States. what we eat in America, NHANES 20052006. Food Surveys Research Group Dietary Data Brief, (3). http://ars.usda.gov/Services/docs.htm?doci d=19476. Physiol Behav, 100: 63-66.

[11] Ranganathan, R.; Nicklas, T.A.; Yang, S.J. and Berenson, G.S. (2005): The nutrition impact of dairy product consumption on dietary intakes of adults (1995-1996): The Bogalusa Health Study. J Am Diet Assoc, 105(9):1391-1400.

[12] Meucci, V.; Razzuoli, E.; Soldani, G. and Massart, F. (2010): Mycotoxin detection in infant formula milks in Italy. Food Addit Contam Part A Chem Anal Control Expo Risk Assess, 27(1): 64-71.

[13]Boudra, H.; Barnouin, J.; Dragacci, S. and Morgavi, D.P. (2007): Aflatoxin M1 and ochratoxin A in raw bulk milk from French dairy herds. J Dairy Sci, 90(7): 3197-3201.

[14]Skaug, M.A. (1999): Analysis of Norwegian milk and infant formulas for ochratoxin A. Food Addit Contam,16(2): 75-78.

[15]Galtier, P. (1991): Pharmacokinetics of ochratoxin A in animals. IARC Sci Publ, 115:187-200.

[16]World Health Organization (WHO) (1991): Technical report series, Evaluation of certain food additives and contaminants. Thirty-seventh report of the Joint FAO/WHO Expert Committee on Food Additives, Geneva.

[17]SCF (1998): Opinion of the Scientific Committee on Food (SCF) on ochratoxin A.

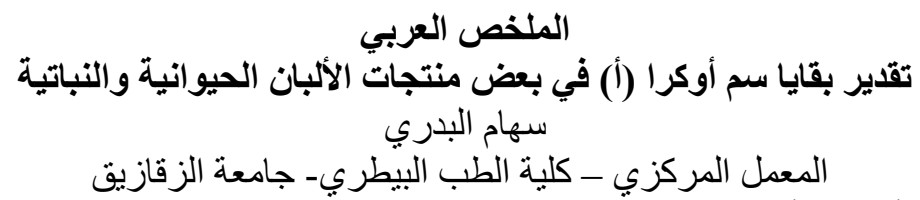

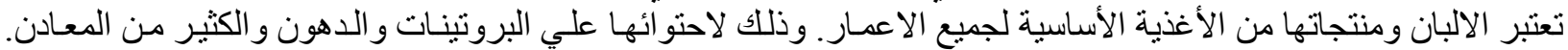

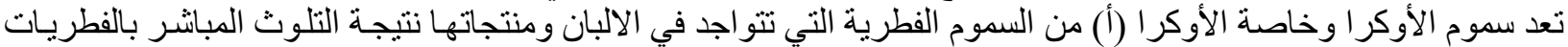

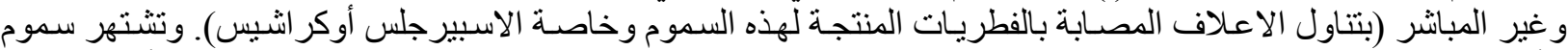

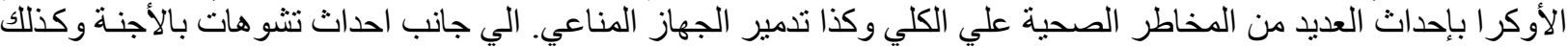

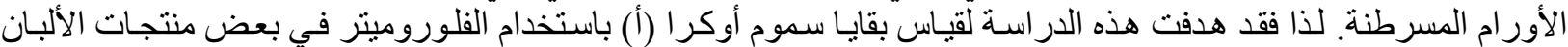

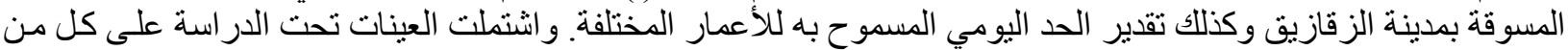

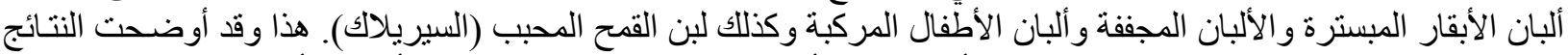

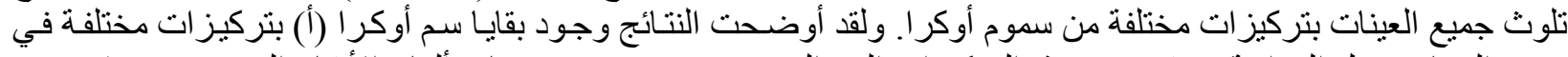

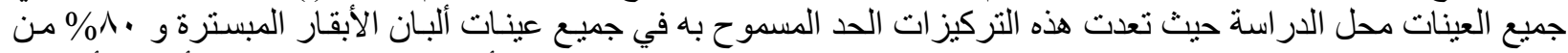

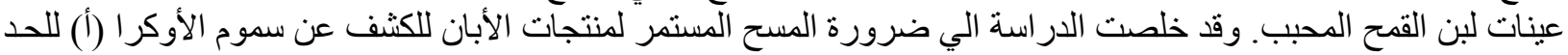
من خطورة هذه السموم علي الصحة العامه. 